\title{
Influence of End Mill Geometry on Milling Force and Surface Integrity While Machining Low Rigidity Parts
}

\author{
Shrikrishna Nandkishor Joshi ${ }^{1}$ (1) $\cdot$ Gururaj Bolar $^{2}$ (])
}

Received: 11 May 2020/Accepted: 13 August 2020/Published online: 4 September 2020

(C) The Author(s) 2020

\begin{abstract}
High precision and superior surface finish are of prime importance in thin-wall components used in the aerospace and automobile industries. In this paper, end milling experiments on aluminum alloy 2024-T351 were carried out to study the influence of end mill geometry on milling force and surface integrity of the machined parts. Machining using a 16-mm-diameter tool having a helix angle of $35^{\circ}$ produced high force value and also generated chatter marks on the machined work surface. Furthermore, an inspection of the cutting tool indicated built-up-edge formation while machining with a $35^{\circ}$ helix tool. Besides, surface damage in the form of surface tear was observed. Evaluation of microhardness revealed an increased value near to the machined surface in the case of two fluted $35^{\circ}$ helix tool due to strain hardening. The results showed that lower milling force and surface roughness were obtained while machining used a four fluted end mill having a diameter of $8 \mathrm{~mm}$ and a helix angle of $55^{\circ}$.
\end{abstract}

Keywords Thin-wall $\cdot$ Helix angle $\cdot$ Tool diameter . Cutting flute $\cdot$ Chatter $\cdot$ Surface roughness

Gururaj Bolar

gururaj.bolar@manipal.edu

1 Department of Mechanical Engineering, Indian Institute of Technology Guwahati, Guwahati 781 039, Assam, India

2 Department of Mechanical and Manufacturing Engineering, Manipal Institute of Technology, Manipal Academy of Higher Education, Manipal 576 104, Karnataka, India

\section{Introduction}

In the modern competitive world, manufacturing industries are continuously thriving for achieving higher productivity and product quality. Also, the trades are striving to produce components in a reasonable time and at lower costs. Components having thin sections are extensively used in aerospace, automobiles, electronic component, and moldmaking industries [1, 2]. But in the machining of thin-wall structures, the cutter enters and exits the material in an interrupted manner leading to the dynamic deflection of the low rigidity parts. The deflection of thin-wall components leads to poor surface finish and dimensional accuracy, thus affecting the service life and performance. Therefore, the thin wall machining process has been analyzed by several researchers.

Ratchev et al. [3] developed an analytical force model to predict the forces while machining straight thin-wall parts. The model integrated the perfect plastic layer model with a finite element model to predict the part deflection and, in turn, the machining forces. Houjun Qi [4] developed an elastic cutting model that took into account the wall deflection and changing workpiece curvature. The developed model predicted with accuracy the force values. Further, the analysis of process parameters revealed that feed per tooth was the primary factor affecting the cutting force.

The cutting forces generated while machining thin-wall parts can induce deformation and lead to a production of dimensionally inaccurate parts. To overcome the problem, several researchers have worked on developing error compensation models. Du et al. [5] developed a coupled force and deformation calculation model to predict and compensate the deformation in thin-wall machining. The force prediction model was based on the shearing 
mechanism and the plowing mechanism and also took into consideration the material properties, tool geometry, and cutting parameters. The deformation was predicted using ANSYS parametric design language (APDL) deformation calculation procedure. The developed model was able to reduce the dimensional errors significantly. Moreover, a model for static deflection and resultant surface error prediction in thin-wall machining using a finite element analysis (FEA)-based approach was developed. The developed model considered shapes of surface error profile based on similarities of axial and radial engagement [6]. Chen et al. [7] established a model based on beam elastic deformation theory to quickly predict the milling force and workpiece deformation.

Chatter is a common cause for tool wear and poor surface finish in the thin-wall machining process. This has directed the researchers to focus their attention on the problem. Feng et al. [8] analyzed the effect of chatter using fast Fourier transform, wavelet transform, and surface topography. They found that chatter can be easily identified using the above techniques during thin-wall machining. An accurate chatter prediction model was developed, which simultaneously considered the influence of material removal, work-tool dynamic behavior, and tool position $[9,10]$.

The thin-wall machining process was studied using three-dimensional (3-D) finite element method-based simulations. The thermomechanical aspects were simulated to predict the transient temperature during the thin-wall machining process, and its influence on part quality was analyzed [11]. The influence of supporting the rib on the thin-wall being machined was analyzed. It was noted that the presence of a supporting rib acted as a constraint and prevented excessive wall deformation [12]. Further, a 3-D simulation was carried out to analyze the influence of cutting force on wall deflection, cutting temperature, and chip morphology [13]. Also, a finite element method-based simulation model was developed to predict the deformation accurately by incorporating the spring back effect in the model [14].

Few experimental studies have been carried out in the area of the thin-wall machining process. Huang et al. [15] analyzed the performance of end mills with variable pitch and uniform pitch while milling titanium alloy thin-part components under dry conditions. Fourier transform and wavelet analysis revealed that tool vibration reduced with the use of variable pitch end mills. The experimental investigation was carried, and regression models for cutting force, material removal rate, and surface roughness were developed in order to optimize the process parameters for machining thin-wall parts. An increase in feed per tooth and milling depth was found to increase the cutting force and surface roughness, whereas the increase in spindle speed reduced the surface roughness and increased the cutting force. Finally, the multi-objective optimization problem was successfully solved using non-dominated sorting genetic algorithm (NSGA-II) [16]. An investigation into the influence of end mill diameter, feed per tooth, axial, and radial depth of cut on machining forces and surface finish was also carried out. It was reported that lower values of feed, axial, and radial depth of cut with a moderate tool size of $8 \mathrm{~mm}$ helped in reducing the surface roughness and cutting forces [17]. Butt et al. [18] designed an apparatus working on non-contact eddy current principle to damp the vibration while machining thin-walled parts. Hammer tests showed successful damping capability of the apparatus with $60 \%$ faster vibration decay after damping. Experiments were conducted to study the influence of spindle speed, feed rate, traverse size, and depth of cut on surface roughness and machining deformation while machining thin-wall parts. The results showed that the surface roughness was influenced by all four parameters, whereas the deformation was mainly influenced by the depth of cut [19]. Further, the analysis of helix angle while machining thin-wall parts revealed that high helix tools are suitable for machining thin-wall parts as they helped in reducing the machining forces and improving the surface finish [20].

Much effort has been directed towards studying the thinwall machining process using the analytical, numerical, and experimental methods by considering the machining process parameters. But, a limited study has been reported on evaluating the influence of end mill geometry parameters during the thin-wall machining process. Therefore, the study attempts to assess the impact of end mill geometry parameters on the milling force, surface finish, and microhardness while machining thin-wall parts.

\section{Materials and Method}

A three-axis $\mathrm{CNC}$ vertical center was used to conduct the experiments (PMK MC-3/400) on the aluminum alloy 2024-T351 workpiece using the experimental setup shown in Fig. 1a. The geometry of the sample workpiece is shown in Fig. 1b. The end mill geometry parameters used for the study were tool diameter, helix angle, and the number of flutes. Figure 1c shows the geometrical characteristics of flat solid carbide end mills used for the study. Machining experiments were performed using a spindle speed of 3500 $\mathrm{r} / \mathrm{min}$, feed per tooth of $0.06 \mathrm{~mm} / \mathrm{z}$, radial depth of cut of $0.625 \mathrm{~mm}$, and axial depth of cut of $12 \mathrm{~mm}$. The thickness of the wall was reduced from 2.5 to $1.25 \mathrm{~mm}$.

Table 1 lists the selected factors and at various levels. A total of nine experiments were conducted based on the L9 Taguchi orthogonal array. Force component measurement 
(a)

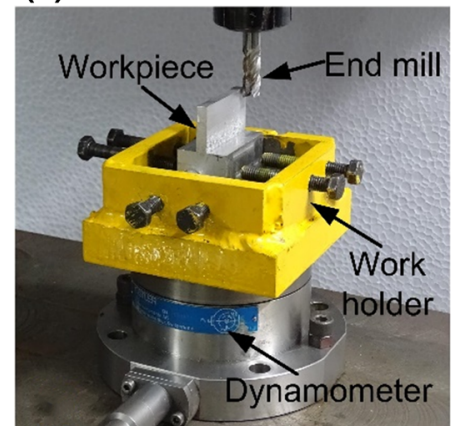

(b)

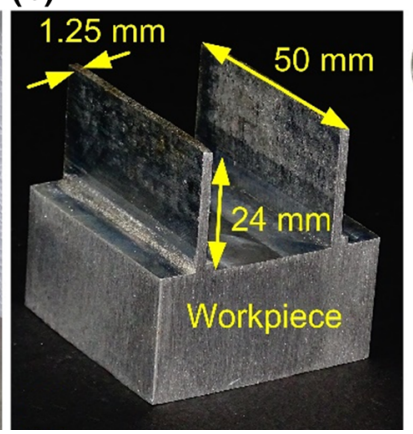

(c)

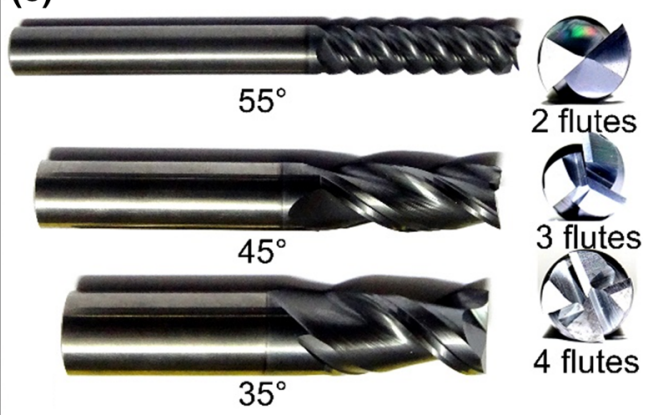

Fig. 1 a Machining setup; b workpiece geometry and dimensions, b end milling tools and related parameters

Table 1 Tool parameters and their levels

\begin{tabular}{llllll}
\hline Design factors & & & \multicolumn{2}{l}{ Levels } & \\
\cline { 5 - 6 } & & & 1 & 2 & 3 \\
\hline Tool diameter & $(\mathrm{mm})$ & & 8 & 12 & 16 \\
\hline Tool helix angle & $\left({ }^{\circ}\right)$ & & 35 & 45 & 55 \\
Number of flutes & $($ Nos. $)$ & & 2 & 3 & 4 \\
\hline
\end{tabular}

was carried using a dynamometer (Kistler 9272B). The machined surface roughness was measured using a noncontact surface profilometer (Talysurf CCI Lite). Measurement was carried out at various locations on the machined surface, and an average value was considered. For the analysis of the microhardness, measurements were done using a digital micro-hardness tester (OmniTech $M V H-I I)$. A load of $300 \mathrm{~g}$ for $5 \mathrm{~s}$ was applied by using Vickers diamond pyramid indenter. The hardness was measured at seven locations along the subsurface of the machined parts.

\section{Results and Discussion}

Table 2 presents the experimental results of surface roughness and milling force components.

\section{Milling Force Analysis}

Knowledge of forces generated during the machining process is essential while designing the machine tools and cutting tools. The machining force also gives a good insight into the quality of the machined surface and power consumed. The magnitude of the milling force is influenced by the chosen process parameters and tool geometry parameters. Therefore, the influence of various tool geometry parameters on milling force components was analyzed, and the variation is shown in Fig. 2.

Figure 2a demonstrates the influence of the helix angle on milling force components during the thin-wall machining process. The magnitude of the resultant force $F_{\mathrm{r}}$ decreases with the increase in the helix angle. The resultant force $F_{\mathrm{r}}$ was higher when an end mill with a helix angle of $35^{\circ}$ was used. The high force value at a low helix angle is related to the work-tool engagement. For a low helix angle tool, due to the steep principle cutting edge, an instantaneous engagement occurs with the work material. This gives rise to the impact load. In addition, the number of axial contact points for a given axial depth of cut is lower in the case of a low helix tool, as seen in Fig. 3. As a result, the volume of material machined is higher at each contact point, which thereby increases the uncut chip volume and, thus, the resultant load. As the value of the helix angle

Table 2 Measured surface roughness and milling force components

\begin{tabular}{llllllll}
\hline Sl. No & Diameter $(\mathrm{mm})$ & Helix angle $\left(^{\circ}\right)$ & Flutes $($ Nos. $)$ & Surface roughness $(\mu \mathrm{m})$ & $F_{\mathrm{x}}(\mathrm{N})$ & $F_{\mathrm{y}}(\mathrm{N})$ & $F_{\mathrm{z}}(\mathrm{N})$ \\
\hline 1 & 8 & 35 & 2 & 0.792 & 76.45 & 64.16 & 19.93 \\
2 & 8 & 45 & 3 & 0.510 & 67.49 & 65.71 & 18.62 \\
3 & 8 & 55 & 4 & 0.370 & 54.64 & 69.97 & 17.4 \\
4 & 12 & 35 & 3 & 1.070 & 85.13 & 72.15 & 19.8 \\
5 & 12 & 45 & 4 & 0.890 & 72.87 & 76.53 & 20.5 \\
6 & 12 & 55 & 2 & 0.940 & 70.23 & 84.01 & 19.34 \\
7 & 16 & 35 & 4 & 1.524 & 96.37 & 81.79 & 18.75 \\
8 & 16 & 45 & 2 & 1.312 & 83.48 & 84.1 & 21.45 \\
9 & 16 & 55 & 3 & 1.394 & 74.05 & 90.66 & 19.66 \\
\hline
\end{tabular}




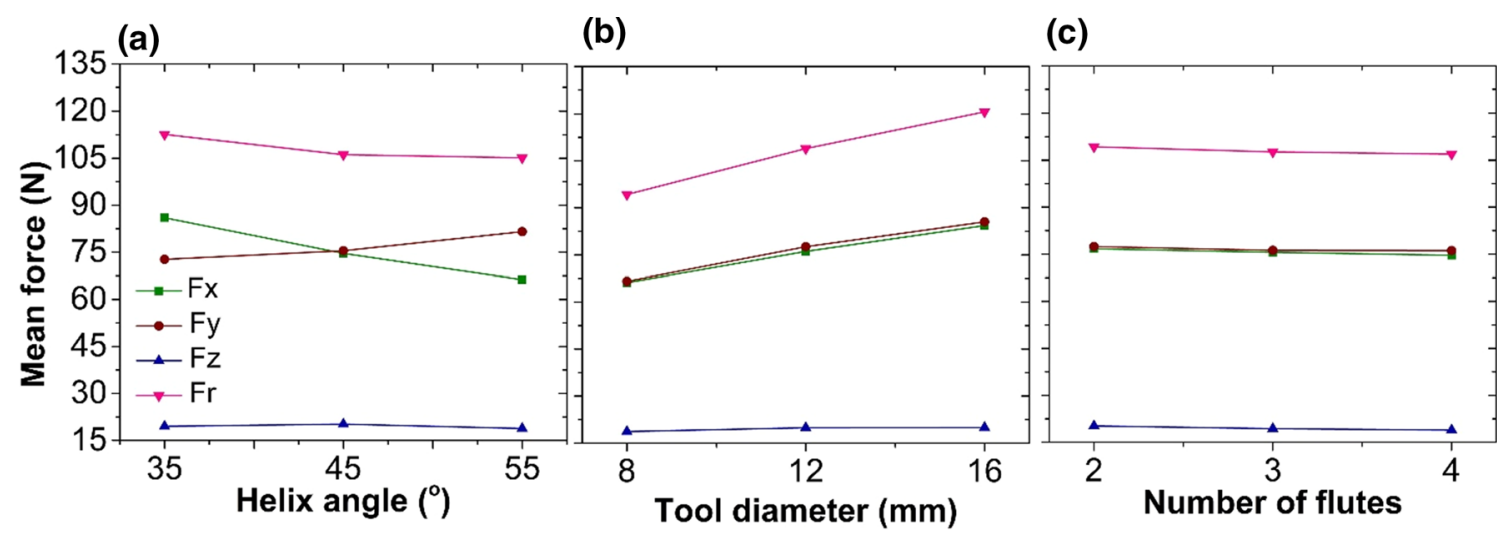

Fig. 2 Variation of mean force components with tool geometry parameters

Fig. 3 Schematic illustrating the influence of milling cutter helix angle on force components

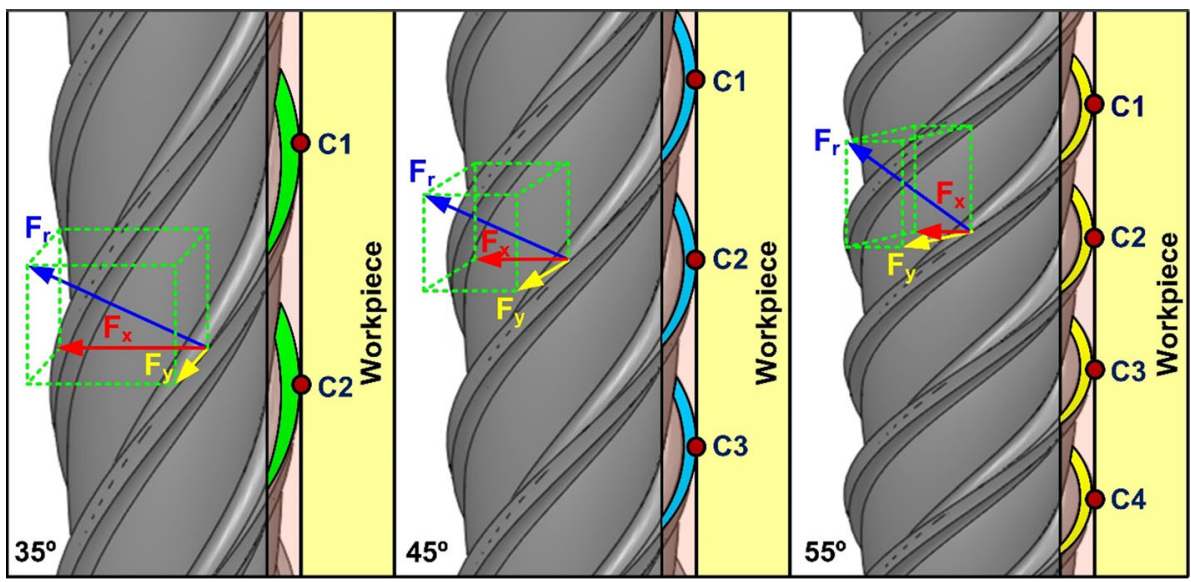

increases, the number of axial contact points increases $[20,21]$. This reduces the volume of the material to be cut by each engaging cutting edge, reducing the force value. The same has been verified by measuring the width of machined chips. Figure 4 a shows the chip generated while machining using a $35^{\circ}$ helix tool. The thickness of the chips varies between 833.3 and $862.71 \mu \mathrm{m}$. With the use of $45^{\circ}$ helix tool, the chip thickness reduces to $656.29-727.85 \mu \mathrm{m}$ and steadily decreases to $611.28-661.86 \mu \mathrm{m}$ when $55^{\circ}$ helix tool is used. Also, machining using a high helix tool reduces the effective rake angle and thereby increases the sharpness of the cutting edge [22]. This helps in smoother and effective machining, thus decreasing the force value. The helix angle also influences the force components $F_{\mathrm{x}}$ and $F_{\mathrm{y}}$. The magnitude of force component $F_{\mathrm{x}}$ decreases, while force component $F_{\mathrm{y}}$ increases with the increase in helix angle. In the case of a $35^{\circ}$ helix tool, the cutting edge is almost vertical. As a result, the $F_{\mathrm{x}}$ force component has a higher magnitude than $F_{\mathrm{y}}$ force component, as seen in Fig. 2a. But, as the tool helix angle increases to $45^{\circ}$ and $55^{\circ}$, the tool cutting edges are directed almost horizontally (see Fig. $2 b, c$ ). This causes the force component $F_{\mathrm{y}}$ as well as the resultant force
$F_{\mathrm{r}}$ to be directed radially. The thrust (axial) force component $F_{\mathrm{z}}$ was found to have a lower magnitude than other force components. The variation of $F_{\mathrm{z}}$ with helix angle shows that the magnitude of the force rises when the machining was carried with a $45^{\circ}$ helix tool but reduces when an end mill with a $55^{\circ}$ helix tool was used.

Change in the end mill diameter influences milling force components, as seen in Fig. $2 \mathrm{~b}$. The resultant force $F_{\mathrm{r}}$ was noted to increase with the tool diameter, a trend noted to be different from the typical peripheral end milling operation. In peripheral end milling, a decrement in the cutting force value is noted with the increase in the tool diameter due to the increase in tool cutting speed [23]. The increase in the resultant force with the tool diameter is associated with the contact width and vibration. When using a larger diameter tool $(16 \mathrm{~mm})$, the width of tool side cutting edge-work contact increases (see Fig. 5). This increases the magnitude of the milling force components. Also, the flexible thinwall components which lack the rigidity to resist the milling force deflect excessively when large-diameter tools are used. The deflection of flexible thin-wall thereby induces dynamic loads. Lower resultant force value was noted with the use of a tool having an $8 \mathrm{~mm}$ diameter. The force 


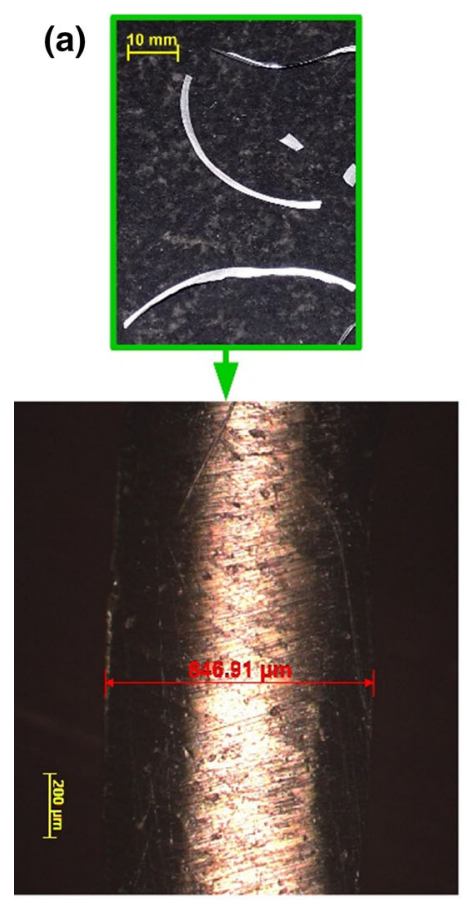

Chip width $=846.91 \mu \mathrm{m}$
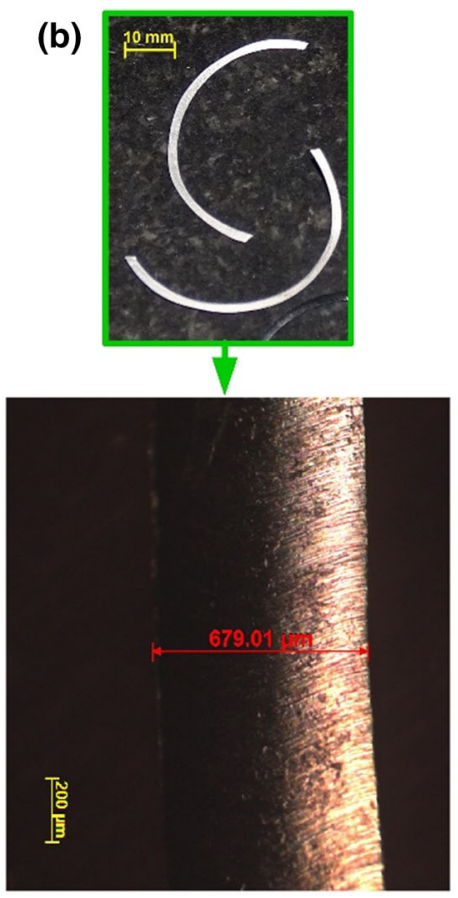

Chip width $=679.01 \mu \mathrm{m}$

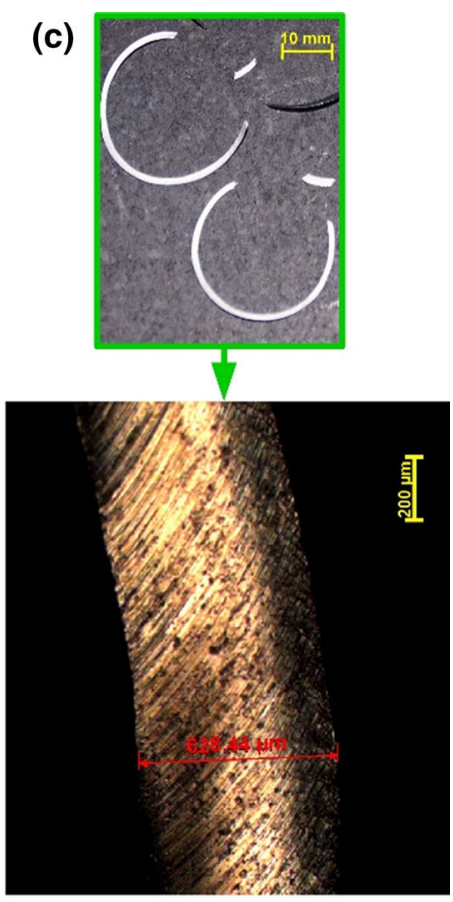

Chip width $=628.44 \mu \mathrm{m}$

Fig. 4 Variation in the chip width while machining with different helix angle tool
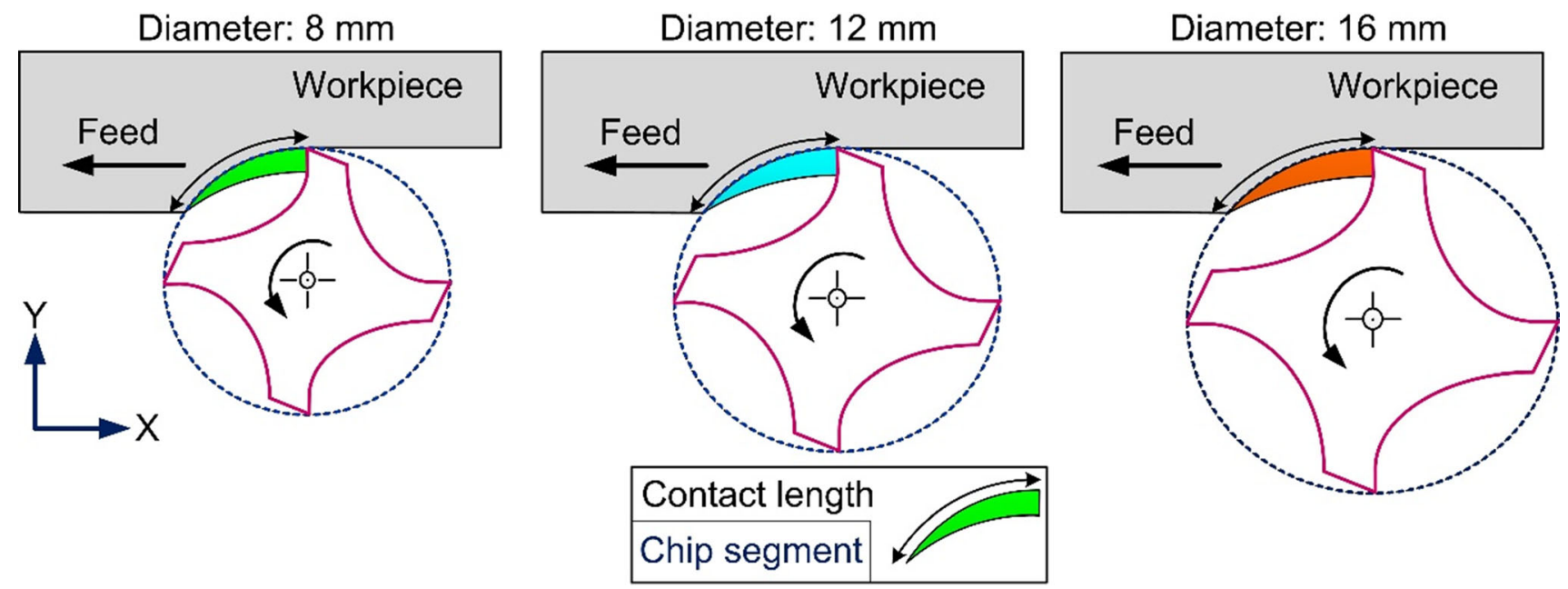

Fig. 5 Influence of tool diameter on work-tool contact length

components $F_{\mathrm{x}}$ (normal to feed direction) and $F_{\mathrm{y}}$ (along feed direction) were found to increase with the tool diameter. In the case of thrust force component $F_{\mathrm{z}}$, the magnitude of the force was lower than the other two force components. But, machining using a $16 \mathrm{~mm}$ tool resulted in slightly higher force value.

Figure 2(c) shows the variation of milling force components with the number of cutting flutes. The milling force components $\left(F_{\mathrm{x}}\right.$ and $\left.F_{\mathrm{y}}\right)$ and resultant milling force $F_{\mathrm{r}}$ were found to reduce with the increase in cutting flutes. For a two flutes end mill, the engagement time of each cutting edge with the workpiece is higher. This increases the chip load and causes the milling force to increase (see Fig. 6). But, for tools with a higher number of flutes, the engagement time of each cutting edge with the workpiece reduces, thus reducing the chip load and milling force.

\section{Surface roughness analysis}

In the end milling process, the roughness of the surface is due to the tooth marks (lay marks) left when machining the surface. These tooth marks are affected by different factors such as tool geometry, workpiece material, and cutting conditions. For a given set of process parameters and tool 

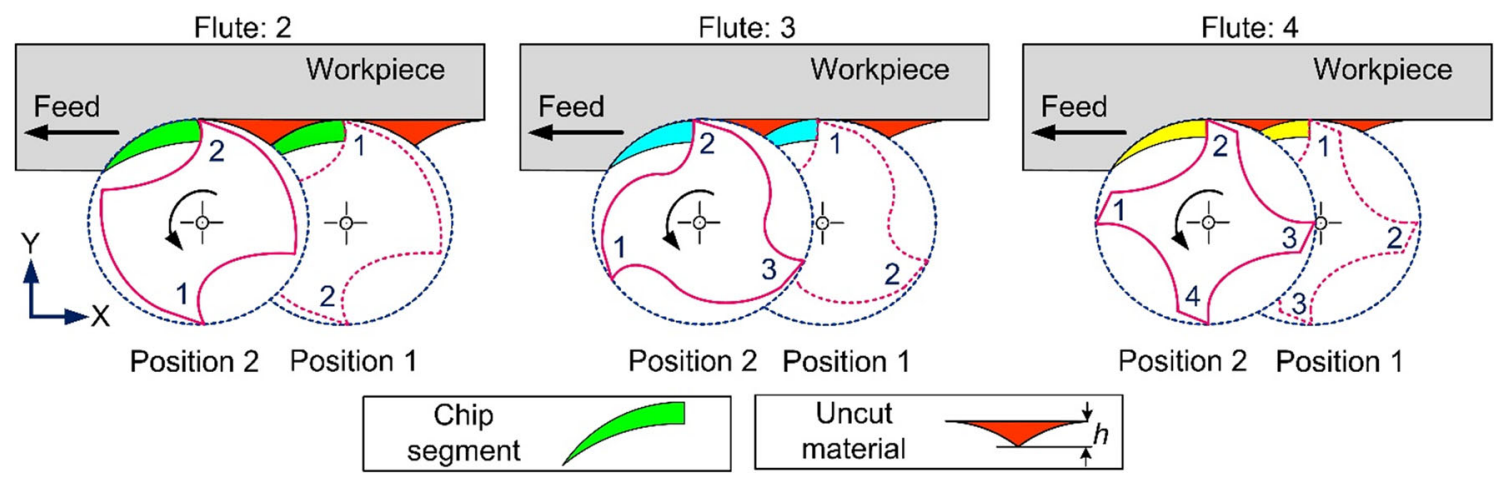

Fig. 6 Schematic illustrating the influence of the number of flutes on milling force and surface roughness

geometry parameters, factors like machining inaccuracies, built-up-edge formation, and chatter can deteriorate the surface finish. Also, the thin-wall components which lack the rigidity to resist the milling force can deflect excessively to induce vibration and chatter. Therefore, the variation surface roughness with tool diameter, helix angle, and the number of tool flutes was studied, and the trends obtained are shown in Fig. 7.

As seen from Fig. 7a, the helix angle of the tool influenced the surface roughness. The surface roughness increased with the helix angle. The tools with smaller helix angles impose stronger shocks to the workpiece during the milling process, causing the instability and chatter and then deteriorating the machined surface finish of the workpiece significantly (see Fig. 8a). As the value of the helix angle increased, the surface roughness decreased, as seen in Fig. 8b, c. With the higher helix tool, reduction in the chip load lowered the milling force. Also, high helix allows for smoother cutting action and chip removal. This helped in reducing the wall deflection and chatter, thus producing improved surface finish.

Figure 7a shows the variation of surface roughness with the tool diameter. Theoretically, the peak-to-valley height of tooth feed marks decreases with the increase in end mill diameter. In the case of thin-wall machining, the roughness of the surface increased with tool diameter. Figure $8 \mathrm{~d}-\mathrm{f}$ shows the 3-D topography of the machined surface with different tool diameters. The surface of the workpiece machined using an 8-mm-diameter tool shows the formation of lay marks, which are characteristic of the milling process (see Fig. 8d). But, the roughness of the surface was found to be lower. As the diameter of the tool increased, the surface finish deteriorated. When a 12-mm-diameter tool was used, the surface roughness increased. This can be attributed to the higher milling force value. Due to the increase in milling force, the thin-wall deflection increased. This resulted in uneven cutting, as seen in Fig. 8e. The use of a 16-mm-diameter tool produced uneven cutting due to dynamic milling force resulting in chatter and vibration, as shown in Fig. 8f.

Figure $7 \mathrm{c}$ shows the variation of the number of flutes with surface roughness. End mills with more flutes provided a much better surface finish. As the number of flute increases, the chip load reduces. This reduces the milling force and wall deflection, thus helping in improving the surface finish.

In addition to the increased surface roughness, damage to surface machined using $35^{\circ}$ helix was noted. Figure 9 shows the 3D topography of the surface machined with a $35^{\circ}$ helix tool. The damage to the machined surface is the result of material being torn away for the surface. Figure $9 \mathrm{a}$ shows the cutting edge of the $35^{\circ}$ helix tool used to

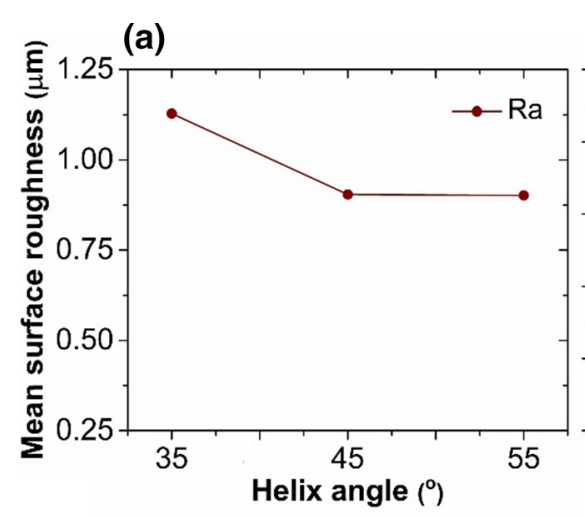

(b)

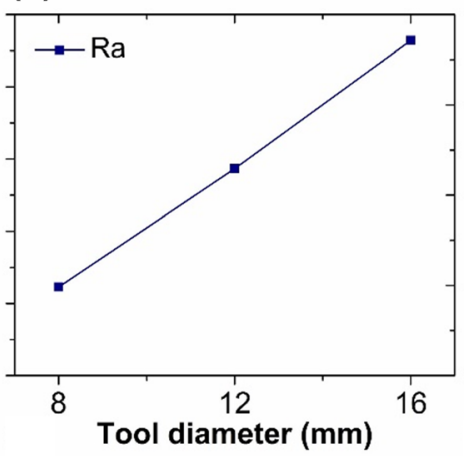

(c)

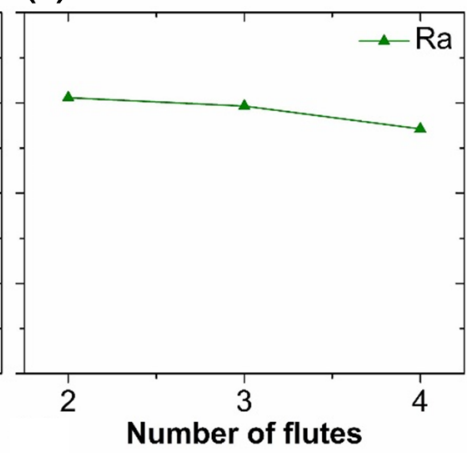

Fig. 7 Variation of mean surface roughness with tool geometry parameters 

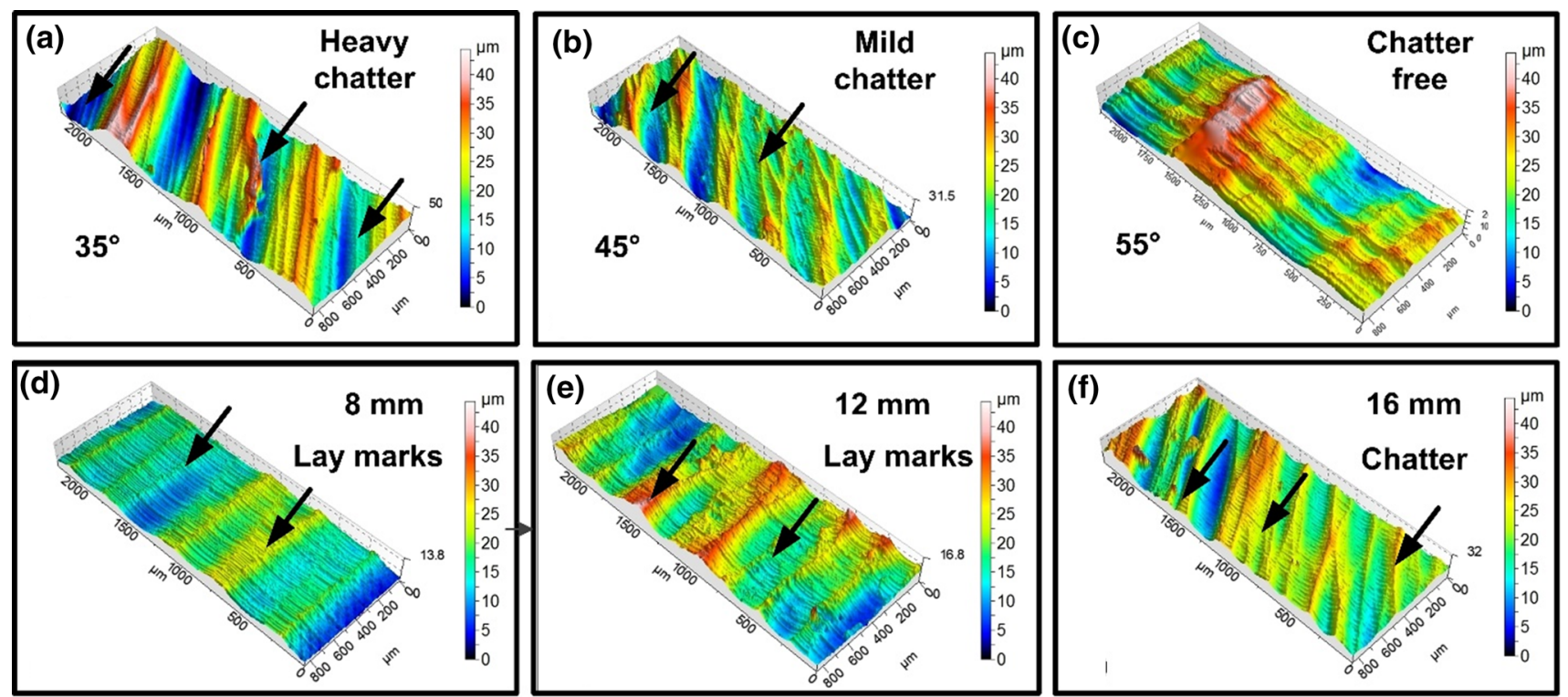

Fig. 8 The topography of the machined surface obtained using a $35^{\circ}$ helix angle; b $45^{\circ}$ helix angle; $\mathbf{c} 55^{\circ}$ helix angle; $\mathbf{d} 8 \mathrm{~mm}$ tool diameter; e $12 \mathrm{~mm}$ tool diameter; $\mathbf{f} 16 \mathrm{~mm}$ tool diameter

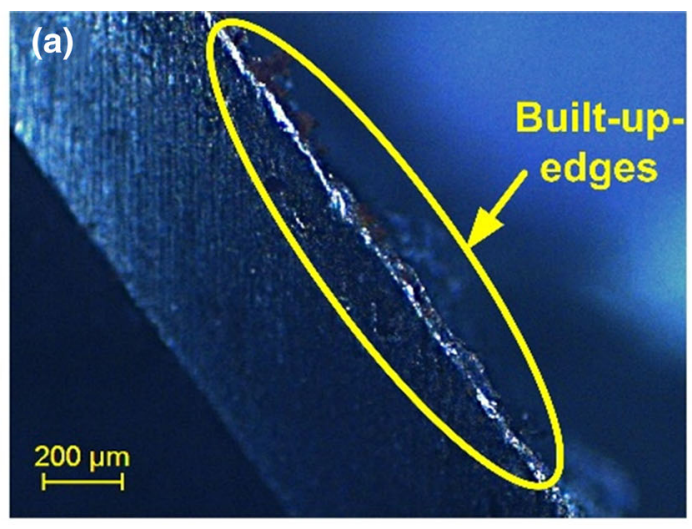

(c)

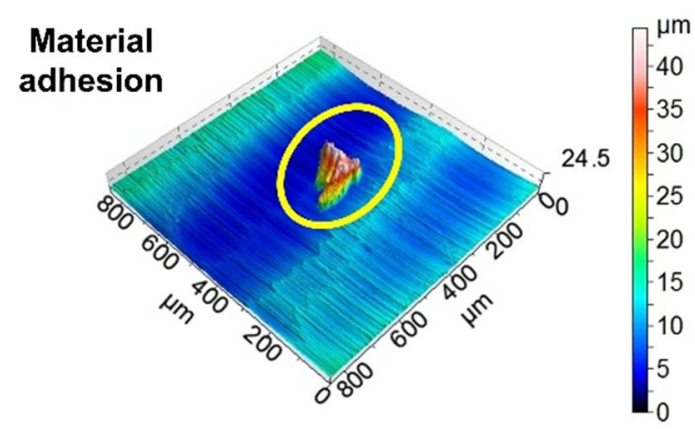

(b)

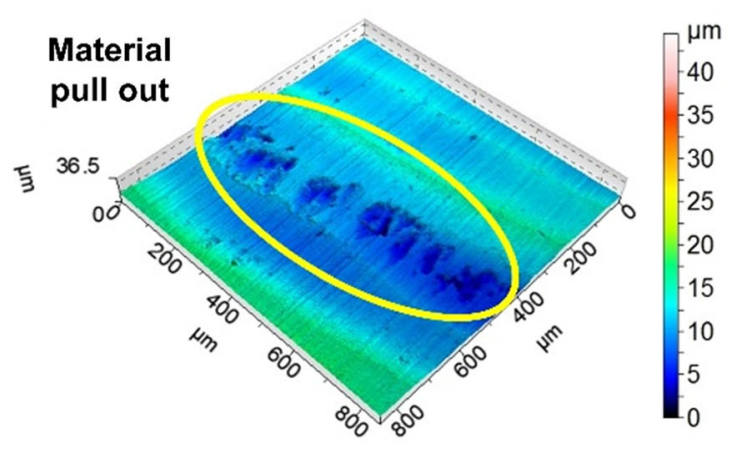

(d)

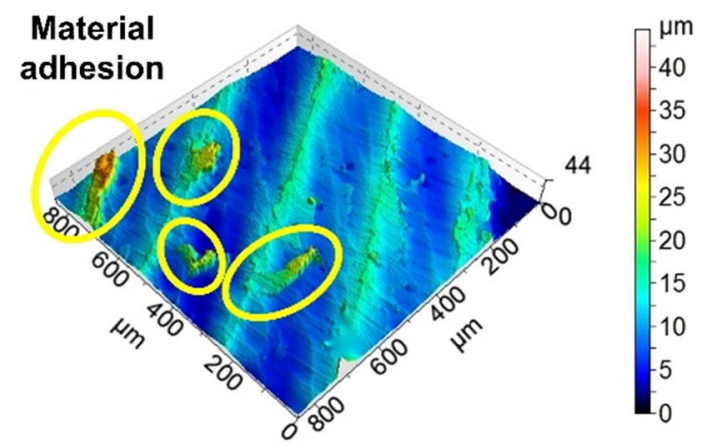

Fig. 9 a Built up edge on a $35^{\circ}$ helix tool; b surface tear; c material adhesion; $\mathbf{d}$ material adhesion

machine the thin-wall part. As noted, the formation of built up edge (BUEs) was observed on the tool cutting edge. The BUE's formed adhered to the work surface. As the machining progressed, the BUE, which adhered to the surface, was pulled out along with the work surface material resulting in a surface tear (see Fig. 9b). Besides, the adhesion of material onto the work surface was noted, as seen in Fig. 9c, d.

\section{Microhardness Analysis}

The surface integrity of the machined surface can be analyzed by studying the surface finish and the microhardness 
(a)

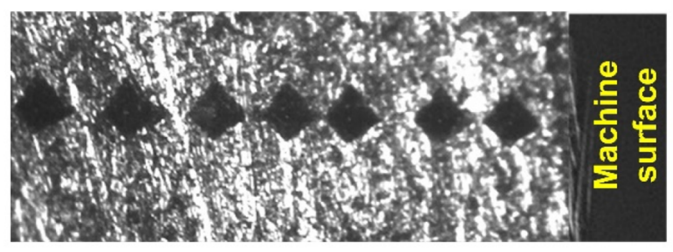

(c)

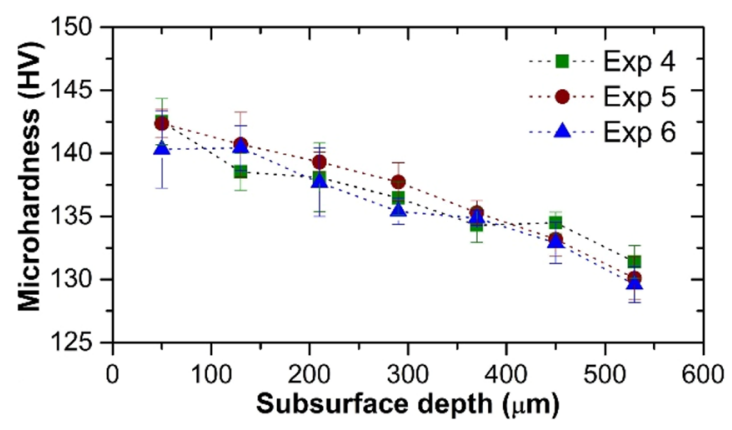

(b)

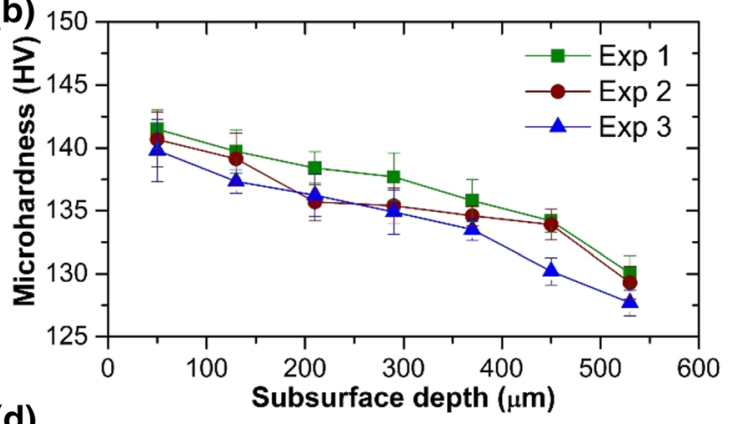

(d)

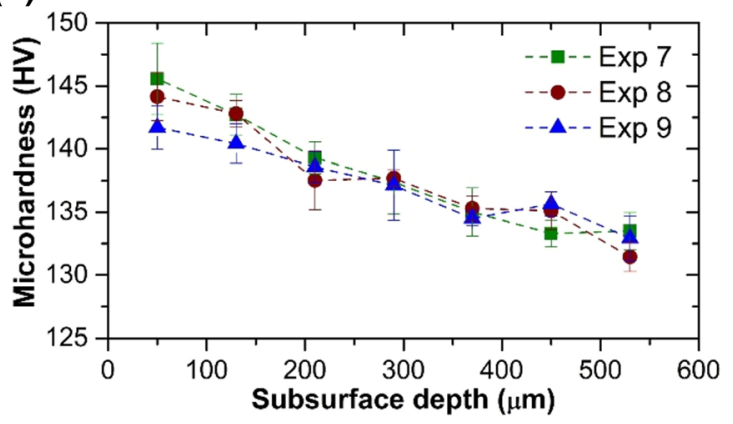

Fig. 10 a Microhardness measurement; b microhardness variation of 8-mm-diameter tools; $\mathbf{c}$ microhardness variation of 12-mm-diameter tools; d microhardness variation of 16-mm-diameter tools

of the machined components. Figure 10 shows the variation in microhardness with cutting tools having different geometry combinations. Microhardness variation was measured up to a depth of $550 \mu \mathrm{m}$ beneath the machined surface, as shown in Fig. 10a. For all the 9 cases, the microhardness near to the work surface was higher than the subsurface hardness. The increase in the hardness can be considered as a function of strain hardening occurring at the machined surface due to the grain refinement and recrystallization due to excessive plastic deformation. The subsurface microhardness gradually reached a stable value due to the reduction in plastic deformation at the subsurface. The variation of microhardness for various tools used is shown in Fig. 10b-d. The values of microhardness were found to be higher when thin-walls were machined using two fluted $35^{\circ}$ helix tools. With the use of a $35^{\circ}$ helix tool, the volume of material to be machined is larger which cause the cutting force to increase. As a result, work material undergoes severe plastic deformation on the machined surface due to strain hardening thereby increasing the microhardness value. In the case of four fluted high helix tools $\left(44^{\circ}\right.$ and $\left.55^{\circ}\right)$, since a lower amount of material undergoes plastic deformation, the cutting forces are lower. Also, efficient shearing and material removal produces lower plastic deformation. As a result, the rise in the microhardness is lower in comparison to a $35^{\circ}$ helix tool.

\section{Conclusions}

In the present work, the influence of end mill geometry on milling force and surface integrity was evaluated while machining thin-wall parts. Measurement of the resultant force revealed that an increased length of tool side cutting edge-work contact with the use of $16 \mathrm{~mm}$ tool diameter increased the magnitude of the resultant milling force. Further, machining with tools having a helix angle of $35^{\circ}$ produced wider chips indicating increased work-tool contact and higher force. The increase in the force magnitude caused the workpiece to deflect, thus resulting in uneven cutting and poor surface finish due to chatter. Also, the use of tools with a $35^{\circ}$ helix angle resulted in formation of built up edges. The adhered BUE leads to material pull out and surface tear. Besides, the adhesion of material onto the work surface was also noted. Machining with a high helix tool increased the sharpness of the cutting edge, which helped in smoother and effective machining, thus decreasing the force value and improving the surface finish. The use of two fluted tools increased the chip load and milling force value, while the increase in the number of flutes reduced the chip load and lowered the milling force and surface roughness. The microhardness of the machined surface revealed a higher value at the work surface than the subsurface. The increase in the hardness is related to the strain hardening occurring at the machined surface due to the excessive plastic deformation. The elevation in microhardness was found to be on the lower side in the 
case of four fluted high helix tools $\left(55^{\circ}\right)$ due to efficient shearing and material removal.

Acknowledgements "This paper is a revised and expanded version of an article entitled, 'Influence of Cutting Tool Geometry Parameters on Milling Forces and Surface Roughness during Thin-Wall Machining Process' presented in '7th International Conference on Advancements and Futuristic Trends in Mechanical and Materials Engineering' held at Indian Institute of Technology Ropar, Rupnagar, India, during December 5-7, 2019”.

Funding Open access funding provided by Manipal Academy of Higher Education, Manipal.

Open Access This article is licensed under a Creative Commons Attribution 4.0 International License, which permits use, sharing, adaptation, distribution and reproduction in any medium or format, as long as you give appropriate credit to the original author(s) and the source, provide a link to the Creative Commons licence, and indicate if changes were made. The images or other third party material in this article are included in the article's Creative Commons licence, unless indicated otherwise in a credit line to the material. If material is not included in the article's Creative Commons licence and your intended use is not permitted by statutory regulation or exceeds the permitted use, you will need to obtain permission directly from the copyright holder. To view a copy of this licence, visit http://creativecommons.org/licenses/by/4.0/.

\section{References}

1. Y. Wang, J. Xie, Z. Wang, N. Gindy, J. Mater. Process. Technol. 205, 338 (2008)

2. Y.G. Kang, Z.Q. Wang, Int. J. Mach. Tool. Manuf. 73, 55 (2013)

3. S. Ratchev, S. Liu, W. Huang, A.A. Becker, J. Mater. Process. Technol. 153, 134 (2004)
4. H. Qi, Y. Tian, D. Zhang, Int. J. Adv. Manuf. Technol. 64, 1599 (2013)

5. Z. Du, D. Zhang, H. Hou, S.Y. Liang, Int. J. Adv. Manuf. Technol. 88, 3405 (2017)

6. N. Arora, A. Agarwal, K.A. Desai, Int. J. Precis. Technol. 8, 107 (2019)

7. Z. Chen, C. Yue, S.Y. Liang, X. Liu, H. Li, X. Li, Int. J. Adv. Manuf. Technol. 107, 4173 (2020)

8. J. Feng, Z. Sun, Z. Jiang, L. Yang, J. Adv. Manuf. Technol. 82, 1909 (2016)

9. Y. Yang, W.H. Zhang, Y.C. Ma, M. Wan, M. Int, J. Mach. Tool. Manuf. 109, 36 (2016)

10. Y. Sun, S. Jiang, Int. J. Mach. Tool. Manuf. 135, 38 (2018)

11. J.K. Rai, P. Xirouchakis, P. Int, J. Adv. Manuf. Technol. 42, 429 (2009)

12. S.N. Joshi, G. Bolar, J. Inst. Eng. Ser. C 98, 343 (2017)

13. G. Bolar, S.N. Joshi, Proc. Inst. Mech. Eng. B J. Eng. Manuf. 231, 792 (2017)

14. L. Si-meng, S. Xiao-dong, G. Xiao-bo, W. Dou, Int. J. Adv. Manuf. Technol. 92, 3503 (2017)

15. P.L. Huang, J.F. Li, J. Sun, J. Zhou, J. Clean. Prod. 67, 258 (2014)

16. S. Qu, J. Zhao, T. Wang, Int. J. Adv. Manuf. Technol. 89, 2399 (2017)

17. G. Bolar, A. Das, S.N. Joshi, Measurement 231, 190 (2018)

18. M.A. Butt, Y. Yang, X. Pei, Q. Liu, Precis. Eng. 51, 682 (2018)

19. D.J. Cheng, F. Xu, S.H. Xu, C.Y. Zhang, S.W. Zhang, S.J. Kim, Int. J. Precis. Eng. Manuf. 21, 1597 (2020)

20. G. Bolar, S.N. Joshi, Int. J. Mach. Mach. Mater. 22, 212 (2020)

21. P. Baowan, C. Saikaew, A. Wisitsoraat, A. Int, J. Adv. Manuf. Technol. 90, 3085 (2017)

22. Y.H. Kim, S.L. Ko, J. Mater. Process. Technol. 130, 653 (2002)

23. S. Anwar, M.M. Nasr, A. Al-Ahmari, M. Alkahtani, B. Abdo, A. El-Tamimi, S. Darwish, Adv. Mech. Eng. 10, 1 (2018)

Publisher's Note Springer Nature remains neutral with regard to jurisdictional claims in published maps and institutional affiliations. 